\title{
A randomized controlled clinical trial for low back pain treated by acupressure and physical therapy
}

\author{
Lisa Li-Chen Hsieh, M.D., ${ }^{a}$ Chung-Hung Kuo, M.D., ${ }^{b}$ \\ Ming-Fang Yen, M.S., ${ }^{a}$ and Tony Hsiu-Hsi Chen, Ph.D. ${ }^{\mathrm{a}, *}$ \\ ${ }^{a}$ Institute of Prevention Medicine, College of Public Health, National Taiwan University, Taipei, Taiwan \\ ${ }^{\mathrm{b}}$ Shen Ho Orthopedic Hospital, Kaohsiung, Taiwan
}

Available online 20 April 2004

\begin{abstract}
Background. Although acupressure has been reported to be effective in managing various types of pain, its efficacy in relieving pain associated with low back pain (LBP) remains unclear. The aim of this study is to compare the efficacy of acupressure with that of physical therapy in reducing low back pain.

Methods. A randomized controlled clinical trial in an orthopedic referral hospital in Taiwan was conducted between December 20, 2000, and March 2, 2001. A total of 146 participants with chronic low back pain were randomly assigned to the acupressure group (69) or the physical therapy group (77), each with a different treatment technique. Self-appraised pain scores were obtained before treatment as baseline and after treatment as outcomes using the Chinese version of Short-Form Pain Questionnaire (SF-PQ).

Results. There were no significant differences in baseline characteristics among patients randomized into the two groups. The mean of posttreatment pain score after a 4-week treatment $(2.28, \mathrm{SD}=2.62)$ in the acupressure group was significantly lower than that in the physical therapy group $(5.05, \mathrm{SD}=5.11)(P=0.0002)$. At the 6-month follow-up assessment, the mean of pain score in the acupressure group $(1.08$, $\mathrm{SD}=1.43)$ was still significantly lower than that in the physical therapy group $(3.15, \mathrm{SD}=3.62)(P=0.0004)$.

Conclusions. Our results suggest that acupressure is another effective alternative medicine in reducing low back pain, although the standard operating procedures involved with acupressure treatment should be carefully assessed in the future.
\end{abstract}

(C) 2004 The Institute For Cancer Prevention and Elsevier Inc. All rights reserved.

Keywords: Low back pain; Acupressure; Physical therapy; Pain score

\section{Introduction}

Epidemiological studies have shown that low back pain (LBP) prevails in the general population with an annual incidence of $5 \%$ and lifetime prevalence of $60-90 \%$ [1]. LBP is a common cause of absence from work as compared to other disorders of the musculoskeletal system [2]. Additionally, several epidemiological studies have shown that LBP entails a $90 \%$ indirect monetary cost as a result of subsequent long-term illness but only a $10 \%$ direct treatment cost [3-6].

Due to recurrence and its negative impact on daily work and life, LBP has long been studied and well documented for its diagnostic classification and management [7]. Aside

* Corresponding author. Institute of Prevention Medicine, College of Public Health, National Taiwan University, Room 207, 2F, No. 19, Hsuchow Road, Taipei, Taiwan. Fax: +886-2-23587707.

E-mail address: stony@episerv.cph.ntu.edu.tw (T.H.-H. Chen). from occidental medication, some people seek alternative medicine such as massage, chiropractic, acupuncture, and acupressure. In the United States, it was estimated that one third of U.S. adults with LBP experienced with alternative medical therapies in 1997 [8]. In Taiwan, the LBP prevalence rate ranges from $35 \%$ to $90 \%$ in different occupation fields [9-11]. Likewise, treatment relies on the physical therapy in the medical system and alternative medicine [12].

As one treatment modality of alternative medicine, acupuncture's efficacy for low back pain remains unproven [13-16]. Related methods such as massage, chiropractic, and acupressure are all based on the manipulative approach. Massage is a muscular-relaxing method for pain relief. Therapeutic massage was demonstrated to be effective for persistent LBP in a randomized trial [17]. However, only short-term benefits were observed. Chiropractic, a manipulative approach that is targeted to the spine, has 
been demonstrated to confer long-term benefits in a randomized trial, in which chiropractic was compared with hospital outpatient treatment for managing LBP [18]. While these manipulative approaches have their strengths and weaknesses, acupressure has now gained increased interest among Taiwanese people. Unlike acupuncture, acupressure, another treatment modality of Chinese traditional medicine, is a gentle but firm pressing stimulation over meridian and acu-points. A brief introduction to acupressure is described in Appendix A. Although acupressure has been reported to be effective in managing various types of pain related to certain diseases [19-24], the efficacy of acupressure in pain relief associated with LBP has never been proven by a randomized controlled clinical trial.

Therefore, the aim of this study is to compare the efficacy of acupressure with physical therapy in reducing LBP. The specific hypothesis was that subjects receiving acupressure may enjoy alone a significant reduction of pain scores compared to those receiving physical therapy.

\section{Methods}

\section{Participants}

The eligibility criteria for subject participation in the study include the following: (1) LBP not caused by severe systematic diseases, that is, SLE or rheumatic disease; (2) no contraindications to acupressure and physical therapy, that is, no open wound, an absence of cancer, or psychiatric disease with the presence of overt clinical symptoms before participation; (3) no severe pain, that is, pain score $>90 \%$; and (4) no surgical operation prescribed by a physician as treatment for his or her LBP. Patients included were from a regional orthopedic hospital in the Kaoshiung, Taiwan area, which offers routine orthopedic operation and rehabilitation of physical therapy.

\section{Sample size}

To determine the required number of samples in this study, estimates of mean and standard deviation in the acupressure group were collected from a pilot study consisting of 23 patients who received acupressure between July 1, 2000, and November 31, 2000. The mean value and standard deviation of pain score after acupressure treatment were estimated as 2.04 and 2.23, respectively. According to these figures, at least 50 subjects were required in each group to reach the difference of four and five score points using Short-Form McGill Pain Score (see below) between physical therapy and acupressure, given a significance level of $5 \%$ and statistical power of $90 \%$.

\section{Interventions}

After excluding patients who could not meet the abovementioned criteria, $88 \%$ (220) were found to be eligible for this study. Written informed consent, indicating rationales for the study and possible advantages and disadvantages to attending this study, was given to each participant. After the informed consent was given, a total of 146 patients between the ages of 16 and 84 years agreed to join the study. The duration of LBP episodes for these patients ranged from 1 month to over 10 years. The majority of patients $(67 \%)$ experienced durations of LBP longer than 6 months. Accordingly, our study included mostly chronic LBP. These patients were randomly assigned to two groups, acupressure and physical therapy, between December 20, 2000, and February 28, 2001. Physical therapy includes thermotherapy, infrared light therapy, electrical stimulation, exercise therapy, and pelvic manual traction. The treatment options selected for each patient were decided by one senior physical therapist. Similarly, the acupressure was performed by a senior therapist who was adept in acupressure.

\section{Randomization}

Upon recruitment, each participant was assigned a random allocation number generated from a random table. Subjects with a digital number from zero to four were assigned to the acupressure group and from five to nine to the physical therapy group. These random allocation numbers were managed by an independent research assistant and not decoded until the intervention was assigned. Application of such a simple randomization procedure yielded 69 patients in the acupressure group and 77 in the physical therapy group.

\section{Blinding}

It should be noted that to reduce the Hawthorne effect (that a known higher pain score will increase the efforts made by the therapist), the therapists in both groups were blind to pretreatment pain scores and were required to write down the date of treatment given to each participant. Patients, without reference to the pretest results, were requested to assess the posttreatment pain scores immediately after the completion of six treatment sessions. Posttreatment pain scores were followed up. The research assistant who conducted the follow-up interviews by telephone was informed beforehand not to ask the participant about the details of intervention to keep blind to the intervention group as much as they can do.

\section{Outcomes}

Both groups received six treatment sessions over a 4week period. In the acupressure group, every treatment lasted approximately $15 \mathrm{~min}$ and was performed by a 
designed senior therapist to render uniform technique and to ensure consistent experience to all patients. The physical therapy group followed the routine practice of the hospital. The participants in each intervention group were requested to fill out baseline information and the questionnaire of pretreatment pain score. The baseline information included date of birth, sex, marital status, level of education, pain visual scale, and pretreatment pain score.

Two separate pain score questionnaires were used for the posttreatment pain score assessment by patients and the 6month follow-up pain score assessment by the research assistant. These questionnaires indicated the reference number and participant's name without revealing the pretreatment pain score.

For pain score measurement, the Chinese version of Short-Form Pain Questionnaires (SF-PQ) [25] was devel- oped. The forward translation method was first performed to yield a Chinese version of SF-PQ. To further check the correlation validity between the original SF-PQ and the Chinese version, 20 persons, who were fluent in both English and Chinese and had experienced LBP, were invited to answer both the original SF-PQ and the Chinese versions simultaneously. The correlation coefficients between the two versions were all higher than 0.8 . Further, the correlation using a visual scale also supports the successful translation of the SF-PQ to the Chinese version.

SF-PQ consists of 15 word descriptors: 1 through 11 representing the sensory dimension of the pain experience, and 12 through 15 representing the affective dimension. Each descriptor was ranked on an intensity scale of $0=$ none, 1 = mild, 2 = moderate, and $3=$ severe. Each

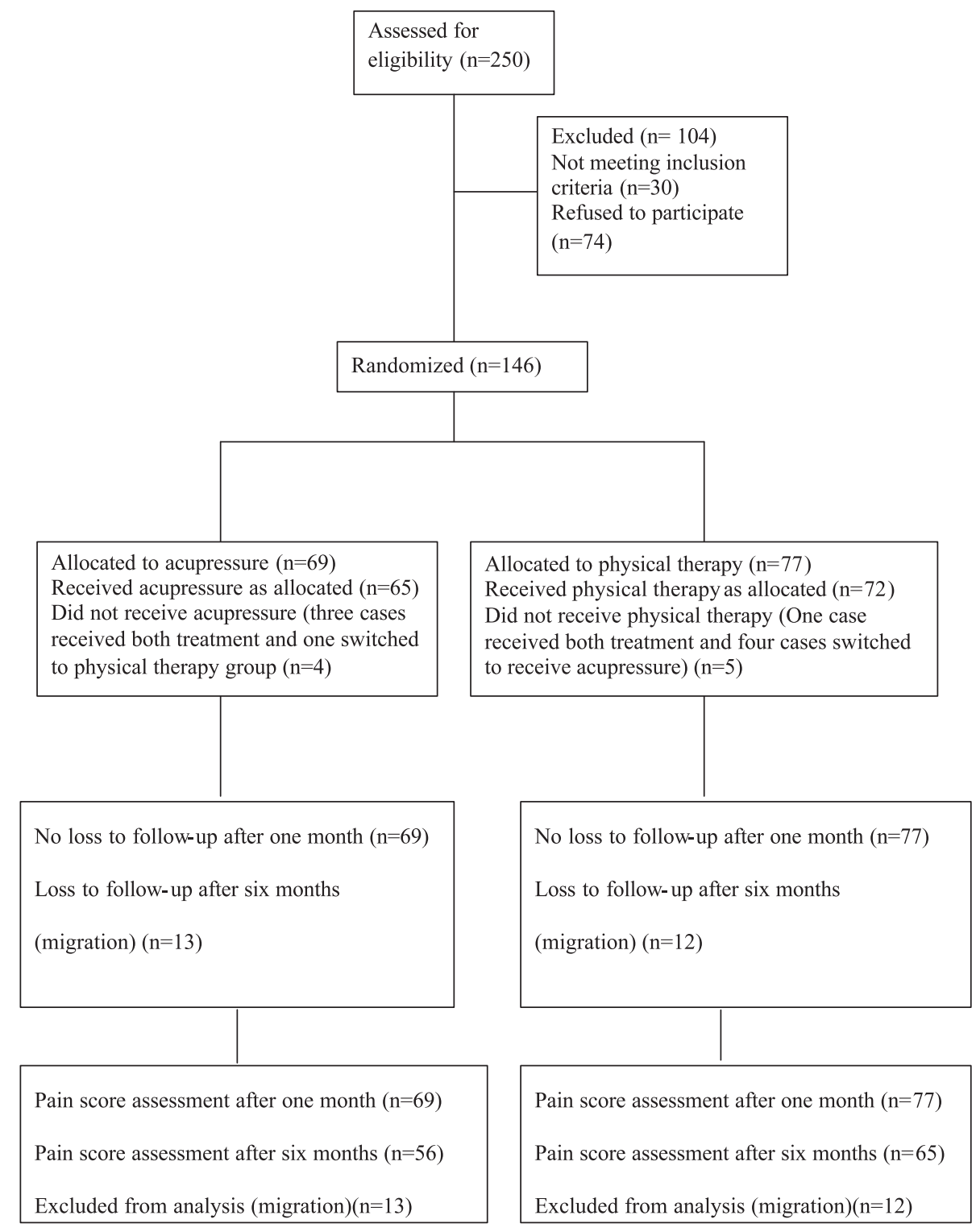

Fig. 1. Flow diagram of subject progress through the phase of a randomized trial. 
Table 1

Comparison of background variables between the acupressure group and the physical therapy group

\begin{tabular}{|c|c|c|c|c|}
\hline Variable & $\begin{array}{l}\text { Acupressure } \\
(n=69)\end{array}$ & $\begin{array}{l}\text { Physical } \\
\text { therapy } \\
(n=77)\end{array}$ & $\chi^{2} / t$ value & $P$ value \\
\hline \multicolumn{5}{|l|}{ Sex } \\
\hline Male & 30 & 40 & 1.046 & 0.31 \\
\hline Female & 39 & 37 & & \\
\hline \multicolumn{5}{|l|}{ Age } \\
\hline Range (years) & $18-78$ & $16-84$ & 0.011 & 0.99 \\
\hline Mean (SD) (years) & $47.6(13.6)$ & $47.6(14.9)$ & & \\
\hline \multicolumn{5}{|l|}{ Marriage } \\
\hline Single & 7 & 9 & 0.089 & 0.77 \\
\hline Married & 62 & 68 & & \\
\hline \multicolumn{5}{|l|}{ Education } \\
\hline College and above & 20 & 15 & & \\
\hline High school & 15 & 29 & & \\
\hline Junior high school & 7 & 12 & 8.095 & 0.15 \\
\hline Primary & 15 & 12 & & \\
\hline None & 7 & 3 & & \\
\hline Unknown & 5 & 6 & & \\
\hline \multicolumn{5}{|l|}{ Occupation } \\
\hline Labor & 15 & 10 & & \\
\hline Office & 21 & 31 & 3.457 & 0.33 \\
\hline Householder & 21 & 19 & & \\
\hline Other & 12 & 17 & & \\
\hline \multicolumn{5}{|c|}{ Pain visual scale $(0-5)$} \\
\hline Range & $0.0-4.0$ & $0.4-5$ & -1.506 & 0.13 \\
\hline Mean & 1.95 & 2.23 & & \\
\hline
\end{tabular}

participant was requested to answer the same 15 items before, immediately following the treatment protocol, and at the 6-month follow-up after the completion of treatment. Summation of these 15 intensity scale numbers yielded a pain score for each participant.

\section{Statistical analysis}

The results from 146 patients were analyzed according to the "intention to treat" approach. The comparisons of background variables between the two treatment groups were made on the basis of independent $t$ test for continuous variables and chi-square test for categorical variables. A nonparametric method, the Wilcoxon ranksum test, was used to detect any significant difference between the two treatment groups of posttreatment pain scores immediately after treatment and at the 6-month follow-up, respectively. Changes made before and after treatment were tested by the Wilcoxon sign-rank test. Taking the median of pretreatment as cutoff points, the relative risk of posttreatment scores above the median of pretreatment score in the acupressure group versus the physical therapy group was calculated to assess the efficacy of acupressure and physical therapy in the relief of pain from LBP. It should be noted that multivariate regression analysis was to be applied if baseline characteristics were dissimilar between the two intervention groups. Otherwise, only univariate analysis using Wilcoxon test was done.

\section{Results}

Fig. 1 provides a diagram of subjects' progress through the phase of a randomized trial. In the acupressure group, 65 patients received acupressure as allocated. Three cases received both treatments and one case switched to receive physical therapy. In the physical therapy group, 72 patients received physical therapy as allocated. One case received both treatments and four cases switched to receive acupressure. At the 6-month follow-up assessment, 56 patients in the acupressure group and 65 patients in the physical therapy group had available information on pain scores. Other subjects could not be traced due to migration. Patients were recruited between December 1, 2000, and February 28, 2001, and followed up until the end of August 2001.

Table 1 shows the comparisons of baseline characteristics between the two treatment groups. There is a lack of significant differences between background variables for the two groups. Patients included in the analysis after completion of the treatment were 69 in the acupressure group and 77 in the physical therapy group. The corresponding numbers for the 6-month follow-up assessment were 56 and 65 . Analysis was based on the intention to treat.

Table 2 shows the comparisons of pain scores between the two groups after completion of treatment and at the 6-

Table 2

Comparison of posttreatment pain scores at 1- and 6-month assessments, respectively, between the acupressure group and the physical therapy group

\begin{tabular}{|c|c|c|c|c|}
\hline Variable & Acupressure & $\begin{array}{l}\text { Physical } \\
\text { therapy }\end{array}$ & $\begin{array}{l}\text { Test } \\
\text { statistics }(Z)\end{array}$ & $P$ value \\
\hline $\begin{array}{l}\text { (1) Assessment } \\
\text { at } 1 \text { month }\end{array}$ & $n=69$ & $n=77$ & & \\
\hline \multicolumn{5}{|c|}{ Posttreatment pain score } \\
\hline Range & $0-11$ & $0-21$ & & \\
\hline Mean (SD) & $2.28(2.62)$ & $5.05(5.11)$ & 3.77 & 0.0002 \\
\hline Median & 2 & 3 & & \\
\hline \multicolumn{5}{|c|}{ Changes of pain score } \\
\hline Range & $-33-0$ & $-10-13$ & 5.08 & $<0.0001$ \\
\hline Mean (SD) & $-7.01(5.80)$ & $-2.64(3.93)$ & & \\
\hline Median & -6 & -2 & & \\
\hline \multicolumn{5}{|c|}{ Posttreatment pain score } \\
\hline$\leq 8^{\mathrm{a}}$ & $66(95.65 \%)$ & $58(75.32 \%)$ & $\chi^{2}=11.75$ & 0.0001 \\
\hline$>8$ & $3(4.35 \%)$ & $19(24.68 \%)$ & & \\
\hline $\begin{array}{l}\text { (2) Assessment } \\
\text { at } 6 \text { months }\end{array}$ & $n=56$ & $n=65$ & & \\
\hline \multicolumn{5}{|c|}{ Posttreatment pain score } \\
\hline Range & $0-6$ & $0-16$ & & \\
\hline Mean (SD) & $1.08(1.43)$ & $3.15(3.62)$ & 3.54 & 0.0004 \\
\hline Median & 1 & 2 & & \\
\hline \multicolumn{5}{|c|}{ Changes of pain score } \\
\hline Range & $-33--1$ & $-15-7$ & & \\
\hline Mean (SD) & $-8.69(5.60)$ & $-4.23(4.70)$ & 4.73 & 0.0001 \\
\hline Median & -7.5 & -4 & & \\
\hline \multicolumn{5}{|c|}{ Posttreatment pain score } \\
\hline$\leq 8^{\mathrm{a}}$ & $55(98.21 \%)$ & $49(75.38 \%)$ & $\chi^{2}=12.98$ & 0.0001 \\
\hline$>8$ & $1(1.79 \%)$ & $16(24.62 \%)$ & & \\
\hline
\end{tabular}

${ }^{\mathrm{a}}$ The median of pretreatment score from both groups. 


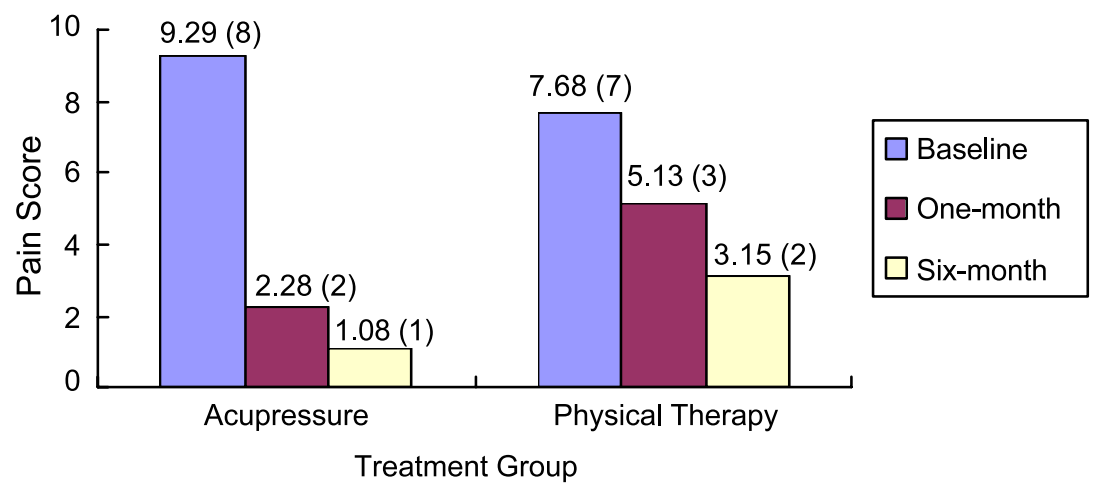

Fig. 2. Comparison of mean (median) pain score in two groups.

month follow-up. The Wilcoxon rank-sum test suggests that the mean of posttreatment pain score after 4 weeks of treatment $(2.28, \mathrm{SD}=2.62)$ in the acupressure group was significantly lower than that in the physical therapy group $(5.05, \mathrm{SD}=5.11)(P=0.0002)$. At the 6-month follow-up assessment, the mean of pain score in the acupressure group $(1.08, \mathrm{SD}=1.43)$ was still significantly lower than that in the physical therapy group $(3.15, \mathrm{SD}=3.62)(P=$ $0.0004)$. Fig. 2 shows changes of pretreatment and posttreatment mean (median) pain scores for the two treatment groups. When the change before and after treatment was taken as the outcome, the Wilcoxon sign-rank test shows a substantial significance difference between the two groups after 4 weeks of treatment $[-7.01(\mathrm{SD}=5.80)$ in the acupressure group and $-2.64(\mathrm{SD}=3.93)$ in the physical therapy group; $P<0.0001]$ and at the 6-month follow-up $[-8.69(\mathrm{SD}=5.60)$ in the acupressure group and -4.23 $(\mathrm{SD}=4.70)$ in the physical therapy group; $P<0.0001]$ (Table 2).

Table 2 also shows posttreatment pain score dichotomized by the median of pretreatment score from both groups. The proportion above the median of pretreatment score in the acupressure group $(4.35 \%)$ was significantly lower than that in the physical therapy group $(24.68 \%)\left[\chi_{(1)}^{2}=9.32, P=\right.$ 0.0023 ] after 4 weeks of treatment. Similar results were also observed at the 6-month follow-up assessments. The relative risks of posttreatment score above the median of pretreatment score in the acupressure group against the physical therapy group were estimated as 0.18 (95\% CI: $0.05-0.60)$ after 4 weeks of treatment and 0.07 (95\% CI: $0.01-0.55)$ at the 6-month follow-up assessment, respectively.

Table 3 shows the comparisons of posttreatment score between the two treatment groups by pain characteristics. There were remarkable differences between the two groups with respect to the pain characteristics of throbbing, shooting, stabbing, sharp, cramping, aching, sickening, and punishing-cruel after 4 weeks of treatment and of cramping, aching, and tiring-exhausting at the 6-month follow-up assessment.

Table 4 shows results of subgroup analysis by age, sex, and pretreatment score. Clearly, the better efficacy of acupressure in pain relief as compared to physical therapy did not vary with age and sex. After completion of treatment, the efficacy of acupressure in pain relief was only found for patients with high pretreatment pain

Table 3

Comparison of the mean of posttreatment scores by pain characters at 1 and 6-month assessments, respectively, between the acupressure group and the physical therapy group, Wilcoxon rank-sum test

\begin{tabular}{|c|c|c|c|c|}
\hline Pain characters & Acupressure & $\begin{array}{l}\text { Physical } \\
\text { therapy }\end{array}$ & $\begin{array}{l}\text { Test } \\
\text { statistics }(Z)\end{array}$ & $P$ value \\
\hline $\begin{array}{l}\text { (1) Assessment at } \\
1 \text { month }\end{array}$ & $n=69$ & $n=77$ & & \\
\hline 1. Throbbing & $0.1014(0)$ & $0.3247(0)$ & -2.74 & 0.0062 \\
\hline 2. Shooting & $0.3043(0)$ & $0.6104(0)$ & -2.23 & 0.0258 \\
\hline 3. Stabbing & $0.0870(0)$ & $0.4675(0)$ & -3.62 & 0.0003 \\
\hline 4. Sharp & $0(0)$ & $0.2987(0)$ & -3.85 & 0.0001 \\
\hline 5. Cramping & $0.1304(0)$ & $0.2987(0)$ & -2.40 & 0.0166 \\
\hline 6. Gnawing & $0(0)$ & $0.0649(0)$ & -1.33 & 0.1823 \\
\hline 7. Hot burning & $0.0145(0)$ & $0.1039(0)$ & -0.91 & 0.3603 \\
\hline 8. Aching & $0.7971(1)$ & $1.2208(1)$ & -2.76 & 0.0057 \\
\hline 9. Heavy & $0.3043(0)$ & $0.4935(0)$ & -0.97 & 0.3310 \\
\hline 10. Tender & $0.2464(0)$ & $0.3636(0)$ & -1.04 & 0.2999 \\
\hline 11. Splitting & $0.0290(0)$ & $0.0909(0)$ & -0.71 & 0.4762 \\
\hline 12. Tiring-exhausting & $0.2174(0)$ & $0.4026(0)$ & -1.55 & 0.1215 \\
\hline 13. Sickening & $0(0)$ & $0.0779(0)$ & -2.14 & 0.0323 \\
\hline 14. Fearful & $0.0145(0)$ & $0.0779(0)$ & -1.24 & 0.2134 \\
\hline 15. Punishing-cruel & $0.0290(0)$ & $0.1558(0)$ & -2.40 & 0.0162 \\
\hline $\begin{array}{l}\text { (2) Assessment at } \\
6 \text { months }\end{array}$ & $n=56$ & $n=65$ & & \\
\hline 1. Throbbing & $0(0)$ & $0.0615(0)$ & -1.61 & 0.1071 \\
\hline 2. Shooting & $0.0357(0)$ & $0.1846(0)$ & -1.76 & 0.0786 \\
\hline 3. Stabbing & $0.0714(0)$ & $0.2154(0)$ & -1.85 & 0.0637 \\
\hline 4. Sharp & $0.0179(0)$ & $0.1077(0)$ & -1.21 & 0.2249 \\
\hline 5. Cramping & $0.0179(0)$ & $0.1846(0)$ & -2.21 & 0.0274 \\
\hline 6. Gnawing & $0(0)$ & $0.0308(0)$ & -0.91 & 0.3620 \\
\hline 7. Hot burning & $0(0)$ & $0.0923(0)$ & -1.61 & 0.1100 \\
\hline 8. Aching & $0.5804(0.25)$ & 0.8339 (1) & -2.82 & 0.0048 \\
\hline 9. Heavy & $0.1786(0)$ & $0.4462(0)$ & -1.74 & 0.0815 \\
\hline 10. Tender & $0.1071(0)$ & $0.2615(0)$ & -1.79 & 0.0735 \\
\hline 11. Splitting & $0.0179(0)$ & $0.0308(0)$ & -0.44 & 0.6571 \\
\hline 12. Tiring-exhausting & $0.0536(0)$ & $0.4308(0)$ & -3.32 & 0.0009 \\
\hline 13. Sickening & $0(0)$ & $0.0308(0)$ & -1.29 & 0.1955 \\
\hline 14. Fearful & $0(0)$ & $0.0154(0)$ & -0.91 & 0.3620 \\
\hline 15. Punishing-cruel & $0(0)$ & $0.0615(0)$ & -1.87 & 0.0613 \\
\hline
\end{tabular}


scores whereas there was the lack of a substantial effect for patients with low pretreatment pain scores. However, a significant benefit was observed for patients with low

Table 4

Subgroup analysis for posttreatment pain scores at 1- and 6-month assessments, respectively, between the acupressure group and the physical therapy group

\begin{tabular}{|c|c|c|c|c|c|}
\hline \multicolumn{2}{|l|}{ Item } & Acupressure & $\begin{array}{l}\text { Physical } \\
\text { therapy }\end{array}$ & $\begin{array}{l}\text { Test } \\
\text { statistics } \\
(Z)\end{array}$ & $P$ value \\
\hline \multicolumn{2}{|l|}{$\begin{array}{l}\text { (1) Assessment } \\
\text { at } 1 \text { month }\end{array}$} & $(n=69)$ & $(n=77)$ & & \\
\hline \multicolumn{6}{|l|}{ Age } \\
\hline \multirow[t]{3}{*}{$\leq 50$ years } & $\begin{array}{l}\text { No. of } \\
\text { cases }\end{array}$ & 41 & 47 & & \\
\hline & Mean (SD) & $2.02(2.3)$ & $5.15(5.19)$ & 3.06 & 0.0023 \\
\hline & Median & 1 & 3 & & \\
\hline \multirow[t]{3}{*}{$>50$ years } & $\begin{array}{l}\text { No. of } \\
\text { cases }\end{array}$ & 28 & 30 & & \\
\hline & Mean (SD) & $2.64(3.05)$ & $4.90(5.06)$ & 2.29 & 0.0221 \\
\hline & Median & 2 & 3 & & \\
\hline
\end{tabular}

Sex

$\begin{array}{llllll}\text { Male } & \begin{array}{l}\text { No. of } \\ \text { cases }\end{array} & 30 & 40 & & \\ & \begin{array}{l}\text { Mean (SD) } \\ \text { Median }\end{array} & 2.47(3.2) & 4.08(4.00) & 2.10 & 0.0356 \\ \text { Female } & \begin{array}{l}\text { No. of } \\ \text { cases }\end{array} & 39 & 37 & & \\ & \begin{array}{l}\text { Mean (SD) } \\ \text { Median }\end{array} & 2.13(2.10) & 6.11(5.96) & 3.29 & 0.0010 \\ & 2 & 3 & & \end{array}$

Pretreatment score

\begin{tabular}{|c|c|c|c|c|c|}
\hline \multirow[t]{3}{*}{ Low $^{a}$} & $\begin{array}{l}\text { No. of } \\
\text { cases }\end{array}$ & 37 & 41 & & \\
\hline & Mean (SD) & $1.78(2.00)$ & $2.29(2.33)$ & 1.34 & 0.1799 \\
\hline & Median & 1 & 2 & & \\
\hline \multirow[t]{3}{*}{$\operatorname{High}^{\mathrm{a}}$} & $\begin{array}{l}\text { No. of } \\
\text { cases }\end{array}$ & 32 & 36 & & \\
\hline & Mean (SD) & $2.84(3.13)$ & $8.19(5.60)$ & 4.28 & 0.0001 \\
\hline & Median & 2 & 8 & & \\
\hline $\begin{array}{l}\text { (2) Assessment } \\
\text { at } 6 \text { months }\end{array}$ & & $(n=56)$ & $(n=65)$ & & \\
\hline \multicolumn{6}{|l|}{ Age } \\
\hline \multirow[t]{3}{*}{$\leq 50$ years } & $\begin{array}{l}\text { No. of } \\
\text { cases }\end{array}$ & 34 & 40 & & \\
\hline & Mean (SD) & $0.99(1.40)$ & $3.19(3.92)$ & 2.78 & 0.0055 \\
\hline & Median & 0.75 & 2 & & \\
\hline \multirow[t]{3}{*}{$>50$ years } & $\begin{array}{l}\text { No. of } \\
\text { cases }\end{array}$ & 22 & 25 & & \\
\hline & Mean (SD) & $1.23(1.51)$ & $3.10(3.16)$ & 2.13 & 0.0334 \\
\hline & Median & 1 & 2 & & \\
\hline \multicolumn{6}{|l|}{ Sex } \\
\hline \multirow[t]{3}{*}{ Male } & $\begin{array}{l}\text { No. of } \\
\text { cases }\end{array}$ & 19 & 35 & & \\
\hline & Mean (SD) & $3.32(1.60)$ & $3.14(3.40)$ & 2.01 & 0.0443 \\
\hline & Median & 1 & 2 & & \\
\hline \multirow[t]{3}{*}{ Female } & $\begin{array}{l}\text { No. of } \\
\text { cases }\end{array}$ & 37 & 30 & & \\
\hline & Mean (SD) & $0.96(1.35)$ & $3.17(3.92)$ & 2.58 & 0.0100 \\
\hline & Median & 1 & 1.25 & & \\
\hline
\end{tabular}

Table 4 (continued)

\begin{tabular}{llllll}
\hline Item & Acupressure & $\begin{array}{l}\text { Physical } \\
\text { therapy }\end{array}$ & $\begin{array}{l}\text { Test } \\
\text { statistics } \\
(Z)\end{array}$ & $P$ value \\
\hline $\begin{array}{l}\text { Pretreatment score } \\
\text { Low }^{\text {a }}\end{array}$ & $\begin{array}{l}\text { No. of } \\
\text { cases }\end{array}$ & 29 & 37 & & \\
& Mean (SD) & $0.86(0.16)$ & 2.14 & 2.15 & 0.0319 \\
& & & $(2.75)$ & & \\
& $\begin{array}{l}\text { Median } \\
\text { Nigh }\end{array}$ & 0 & 1 & & \\
& $\begin{array}{l}\text { No. of } \\
\text { cases }\end{array}$ & 27 & 28 & & \\
& Mean (SD) & $1.31(1.67)$ & 4.50 & 3.15 & 0.0016 \\
& & & $(4.20)$ & & \\
& Median & 1 & 4 & &
\end{tabular}

${ }^{a}$ Median was used to classify the low or high group. The median of pretreatment score for the acupressure group was 8 , and 7 for acupressure group and the physical therapy group.

pretreatment pain scores at their 6-month follow-up assessment.

It should be noted that no adverse direct of side effects were reported in the acupressure group.

\section{Discussion}

To the best of our knowledge, this was the first randomized clinical trial to compare acupressure with physical therapy in reducing LBP. The result suggests that acupressure may be more efficacious in alleviating LBP than physical therapy. The relative treatment efficacy with regard to pain relief from acupressure as compared to physical therapy was about $82 \%[(1-0.18) \times 100 \%]$ (95\% CI: $40 \%-95 \%)$ after 4 weeks of treatment and 93\% (95\% CI: 45-99\%) at 6-month follow-up assessment. Therefore, acupressure is a useful solution for pain relief associated with cramping, aching, tiring-exhausting. Results from subgroup analysis show acupressure was more efficacious than physical therapy regardless of age or sex.

However, it should be noted that the effectiveness of any manipulation therapy is highly dependent upon the therapist's technique and experience. The treatment modality in either physical therapy or acupressure should be standardized so as to ensure comparability between treatments. For physical therapy, this should not be a serious problem because the technique has been well established. For acupressure, since there are a limited number of therapists in acupressure and the standardization of the technique is thus rather difficult to ascertain, only one therapist was involved in our study to avoid the variation. The use of a solo therapist may enhance internal validity but also imposes a threat to external validity. The establishment of standardized process and evidence-based assessment for an acupressure therapist is strongly recommended for future studies. 
In addition, although the present study demonstrated the efficacy of acupressure in pain relief, it can be argued that the feeling of pain relief may be a result of the psychological therapy emerged between patients and the therapist while applying therapy. The interaction or a doctor-patient relationship should be considered an important factor. However, this factor may not seriously impact our study due to two reasons: (1) our patients are recruited from an orthopedic hospital; and (2) generally, Chinese patients with a strong desire to seek physical therapy engage in open communication with orthopedists. Therefore, psychological effect arising from acupressure should not be much different from that from physical therapy.

The theory of acupressure therapy is based on the human body's physiological meridian and acu-points. Its therapeutic effects are dependent upon not only the therapist's technique and experience but also the level of Qi he or she has. Qi, may be defined as the human life energy, naturally endowed to each individual whit, may be enhanced through breathing exercises. The higher the Qi possessed, the better the therapist's performance of the treatment. Qi is crucial for pain relief when acupressure is applied. The more Qi received by patients from the therapist should result in more pain relief. This suggests that the energy level of Qi possessed by the therapist plays an important role in the effectiveness of the treatment. In other words, the effectiveness of treatment varies by different therapist. And therefore to avoid the variation in this study, only one therapist conducted acupressure therapy. Acupressure has been reported effective in pain control in case studies for certain diseases such as LBP, neck pain, and headache. Due to heterogeneity of practice, it was very difficult to conduct randomized clinical trials to demonstrate the efficacy of pain control in LBP specifically. Our results, based on a randomized control clinical trial, suggest that acupressure provides favorable results in pain relief. This supports the efficacy of acupressure underpinning the theory of human body's physiological meridian and acupoints in reducing LBP. This finding has significant implications for providing alternative treatment to patients with LBP because acupressure is a simple and noninvasive treatment. Although the present study demonstrated the efficacy of acupressure in reducing LBP, this does not mean acupressure should replace physical therapy but only that acupressure may provide an alternative method for treating LBP. Since the efficacy of acupressure is highly dependent on the therapist's technique and experience, the treatment of LBP with this treatment alternative should be very carefully assessed.

Seventy-four patients refused to participate in this study. The study population only consists of 146 attendants. To understand whether these attendants adequately represent the target population that would have visited this regional hospital had they had suffered from LBP, a comparison of background variables in both groups was undertaken. Of the 74 nonattendants, information on background variables was available for only 40 subjects. We compared 146 attendants with 40 nonattendants with respect to the distributions of background variables and found that there lacked any significant differences between the two groups (data not shown). This suggests that attendants in this study may represent the target population.

One major limitation in this study is that the outcome measurement for LBP did not measure functional status or disability as suggested in LBP research [26]. This makes the comparison of our result with international studies difficult. However, as our aim was to assess pain relief after acupressure, we used the pain score as our primary measurement. Functional status and disability should be measured in future studies to make comparison with international studies.

In conclusion, a randomized controlled clinical trial was conducted to demonstrate the efficacy of acupressure in pain relief for patients with LBP compared to that provided by physical therapy. However, it is important to note that external applications and standardized procedure of the acupressure for LBP should be carefully assessed in the future.

\section{Appendix A. Brief introduction to acupressure}

Acupressure, one of the therapeutic modalities in traditional Chinese medicine, has been used for relieving pain, illness, and injuries for centuries [27].

"Qi-Blood Theory" [28], one major theory in traditional Chinese medicine, considers that all human life is empowered by a life energy force called Qi. Qi, as "matter" on the verge of becoming energy, or energy at the point of materializing, and not some primordial, immutable material nor merely a vital energy. Traditional Chinese thought does not distinguish between matter and energy and asserts that the functioning of body and mind is supported by Qi and by the other vital substances that are manifestations of Qi. In other words, the basis of all is Qi: All other vital substances are manifestations of Qi in varying degrees of materiality, ranging from the complete material, such as body, blood, and fluids, to the totally immaterial, such as the mind, energy, and air $[29,30]$. Therefore, health is maintained by the smooth flow of life energy-Qi through pathways in our bodies called meridians. According to "Meridians Theory" $[31,32]$, meridians act as conduits that maintain balance and health throughout our body's skin, muscle, and organs. Along meridians are numerous acu-points that serve as external doors or openings to the meridians that access the internal tissues and organs of the body. They transport Qi and material so that our body can function smoothly. When injuries, emotions, disease, stress, or poor lifestyle disrupt the normal circulation of air, blood, lymph, and other fluids in our body, we begin to feel ill.

The electrical properties of the skin along meridian and acu-points are different from nonmeridian and acu-point locations. If an organ is removed or the tissue crossed by 
the meridian is destroyed, the electrical potential decreases or possibly even disappears. Meridians work as a conduit in the body, similar to the nervous system, but do not follow all of its rules. Evidence suggests that stimulation of acu-points can bring about the release of opioid peptides, activate the hypothalamus and pituitary glands, modify blood flow, alter immune function, and affect the secretion of neurotransmitters and neurohormones [33].

According to the National Institutes of Health's consensus statement from its November 1997 conference, "Acupuncture describes a family of procedures involving stimulation of anatomical locations on the skin by a variety of techniques. There are a variety of approaches that incorporate medical traditions from China, Japan, Korea, and other countries" [34]. In 1997 and 2000, the Center for Complementary Health Studies reported up to 30 complementary or alternative therapies. Alternative therapies were classified into three groups. Acupuncture was classified as a Group 1 therapy: "the professionally organized alternative therapies" [35]. In May 2001, WHO publications and documents on Traditional Medicine for Acupuncture and for Research and training defined acupuncture as, "Acupuncture literally means to ... and may also involve the application of other kinds of stimulation to certain points. In this publication, the term acupuncture is used in its broad sense to include traditional body needling,... and acupressure (the application of pressure at selected sites)" [36].

Acupuncture was the first therapeutic technique of Chinese medicine to reach the Western medical community. Its therapeutic value and results of treatment have been tested affirming its growing and universal acceptance. In contrast, acupressure was less studied and documented for its medical effects and applications although it may contribute significantly to relieving pain, illness, and injuries [37].

Acupressure, as a family branch of acupuncture, is a gentle but firm pressing stimulation mainly by fingers over meridians and acu-points, which are the doorways leading in and out of our body and act as monitoring points for the functioning of human organs. Each acu-point represents a particular tissue, organ, or system and reflects the body's physical conditions; therefore, stimulating these acu-points influences the body's ability to function regarding the respective tissues or organs. The same meridian and acupoints are used as in acupuncture, but acupressure is carried out without the use of needles. In addition, acupuncture is contraindicative to patients with certain diseases and to certain acu-points that are prohibited from needling. Acupressure, however, can access nearly all acupoints. Although identical acu-points may be used in acupuncture and acupressure, acupuncture is limited to the exact insertion of a needle into an acu-point, whereas a senior acupressure practitioner can easily control the flow and action of his or her Qi through remote points that access any and all acu-points. Acupressure is a means to cure and/or alleviate certain illnesses and can be a method to screen for and detect illnesses by a well-trained acupressure therapist through the acu-point-reflecting-pain held by each acu-point, which reflects each patient's specific body condition [37]. Generally, this technique is not dangerous and can be combined with other types of therapy.

Acupressure uses the human body as the only treatment tool. Also, there is a diminished degree of risk when using a skillful therapist. It is often performed while patients are fully clothed on a table. The treatment lasts from a few minutes to a couple of hours, depending upon the therapist's techniques and decisions. Acupressure therapists are usually requested to have practiced beforehand the medical Qigong through persistent breathing exercise and to have learnt the general principles of Chinese medicine including meridians and acu-points to improve the treatment effects. As a result, the therapist may use his or her own body to help patients by transferring his or her own Qi to the patient's body through pressing meridians and/or acu-points.

Ideally, therapists should have a basic understanding of modern medical science to address those more "scientifically based" questions generally presented in Western culture. Based on the abovementioned techniques and theories, acupressure may be considered a safe and effective method of treatment for people with a variety of lifestyles under most circumstances.

\section{References}

[1] Malanga GA, Nadler SF. Non-operative treatment of low back pain. Mayo Clin Proc 1999;74:1135-48.

[2] Oland G, Tveiten G. A trial of modern rehabilitation for chronic lowback pain and disability. Vocational outcome and effect of pain modulation. Spine 1991;16:457-9.

[3] Rosen M. Clinical Standards Advisory Group. Back Pain. London: HMSO; 1994.

[4] van Tulder MW, Koes BW, Bouter LM. A cost-of-illness study of back pain in the Netherlands. Pain 1995;62:233-40.

[5] Andersson G. The epidemiology of spinal disorders. In: Frymoyer J, editor. The adult spine: principles and practice. Philadelphia: Lippincott-Raven; 1997. p. $93-141$.

[6] Nachemson A, Waddell G, Norlund A. Epidemiology of neck and low back pain. In: Nachemson A, Jonsson E, editors. Neck and back pain: the scientific evidence of causes, diagnosis and treatment. First ed. Philadelphia: Lippincott, William \& Wilkins; 2000. p. 165-87.

[7] Spitzer W, LeBlanc F, Dupuis M. Scientific approach to the assessment and management of activity-related spinal disorders. A monograph for clinicians. Spine 1987;12:S1-S59.

[8] Eisenberg DM, Davis RB, Ettner SL, et al. Trends in alternative medicine use in the United States, 1990-1997: results of a followup national survey. JAMA 1998;280:1569-75.

[9] Liu JS, Wen TS, Su WL. Prevalence of low back pain among Chinese air-force pilot. J Chin Aviat Med Assoc 1999;12:77-83.

[10] Mah C. Low back pain and associated factors among nursing staff in a medical center. Master thesis, Institute of Nursing, National Defense Medical College; 2001. 
[11] Yao CC. Subjective experience and on-site intervention of musculoskeletal symptoms among camera journalists. Master thesis, Institute of Industrial Engineering and Management, Chung Hwa University; 2001.

[12] Chu IM. An analysis of acute low back pain medical utilization. Master thesis, Institute of Medical Practices Management, Chinese Medical College; 2001.

[13] Ernst E, White AR. Acupuncture for low back pain: a meta-analysis of randomized controlled trial. Arch Intern Med 1998;158:2235-41.

[14] Ernst E. Massage therapy for low back pain: a systematic review. J Pain Symptom Manage 1999;17:65-9.

[15] NIH. Consensus conference: acupuncture. JAMA 1998;280:1518-24.

[16] van Tulder MW, Assendelft WJJ, Kose BW, Bouter LM. The editorial board of the Cochrane Collaboration Back Review Group. The effectiveness of acupuncture in the management of acute and chronic low back pain: a systematic review within the framework of the Cochrane Collaboration Back Review Group. Spine 1999;24:1113-23.

[17] Cherkin DC, Eisenberg D, Sherman KJ, Baarlow W, Kaptchuk TJ, Street JRN, et al. Randomized trial comparing traditional Chinese medical acupuncture, therapeutic massage, and self-care education for chronic low back pain. Arch Intern Med 2001;161:1081-8.

[18] Meade T, Dyer S, Browne W, Townsend J, Frank A. Low back pain of mechanical origin: randomized comparison of chiropractic and hospital outpatient treatment. BMJ 1990;300:1431-7.

[19] Allison DB, Kreibich K, Heshka S, Heymsfield SB. A randomised placebo-controlled clinical trial of an acupressure device for weight loss. Int J Obes Relat Metab Disord 1995;19:653-8.

[20] Nguyen HP, Le DL, Tran QM, Nguyen VT, Nguyen NO. CHROMASSI: a therapy advice system based on chrono-massage and acupression using the method of ZiWuLiuZhu. Medinfo 1995;8:998.

[21] Cook A, Wilcox G. Pressuring pain. Alternative therapies for labor pain management. AWHONN Lifelines 1997;1:36-41.

[22] Maxwell J. The gentle power of acupressure. RN 1997;60:53-6.

[23] Stone RG, Wharton RB. Simultaneous multiple-modality therapy for tension headaches and neck pain. Biomed Instrum Technol 1997; 31:259-62.

[24] Dibble SL, Chapman J, Mack KA, Shih AS. Acupressure for nausea: results of a pilot study. Oncol Nurs Forum 2000;27:41-7.

[25] Melzack R. The short-form McGill Pain Questionnaire. Pain 1987;30: $191-7$

[26] Deyo RA, Battie M, Beurskens AJHM, Bombardier C, Croft P, Koes $\mathrm{B}$, et al. Outcome measures for low back pain research. Spine 1998;23:2003-13.

[27] Wei LY. Acupuncture science and technique. Taipei: Taiwan Chung Hwa Publications; 1986. p. $202-9$.

[28] Lee DH. Qi Shiee Luenn. Taipei: Chih Yuan Publications; 1996. p. $51-94$.

[29] Kapichuk T. The Web that has no weaver. New York: Congdon and Weed; 1983.

[30] Maciocia G. Foundations of Chinese medicine. London: Churchill Livingstone; 1989

[31] Dai HM. Chinese medicine. Taipei: Chi Yeh Publications; 1986. p. $52-72$.

[32] Kawashima K. The acupuncture anatomy. Taipei: Wu Lin Publications; 1992. p. 303-9.

[33] Villaire M. NIH consensus conference confirms acupuncture's efficacy. Altern Ther Health Med 1998;4:21-30.

[34] National Institute of Health Consensus Development Conference Statement. Acupuncture; November 3-5, 1997.

[35] Mills SY. Regulation in complementary and alternative medicine. BMJ 2001;322:158-60.

[36] WHO. Acupuncture: review and analysis of reports on controlled clinical trials; May, 2001.

[37] Hsieh LC. The study on the effectiveness of Qigong therapy via acu-points and the finding of the new effect of points and their possibility of the use of instruments. Conference on Engineering Technology and Applications to Chinese and Western Medicine 1998;231-5. 